\title{
Internet Addiction among Undergraduate Students: Evidence from a Malaysian Public University
}

Rosliza A.M. ${ }^{a}$, Ragubathi M.N. ${ }^{b}$, Mohamad Yusoff M.K.A ${ }^{b}$, Shaharuddin M.S. ${ }^{c}$

${ }^{a}$ Department of Community Health, Faculty of Medicine and Health Sciences, University Putra Malaysia

${ }^{b}$ Second Year Medical Student, Faculty of Medicine and Health Sciences, Universiti Putra Malaysia

'Department of Occupational and Environmental Health, Faculty of Medicine and Health Sciences, Universiti Putra Malaysia

\section{ABSTRACT}

Introduction: Internet addiction is an increasingly worrying phenomena affecting people globally especially the youths. This study aimed to determine the prevalence of internet addiction among undergraduate students in a Malaysian public university and its associated factors. Materials and Methods: A cross-sectional study involving 322 undergraduate students, identified through cluster sampling was conducted using a pretested, self-administered questionnaire. The questionnaire includes socio-demography, use of information technology gadgets and internet usage. Internet Addiction test (IAT) was used to identify internet addiction. Data was analysed using SPSS version 22. Results: From 322 respondents, 25 (7.8\%) were categorised as addictive internet users, while 182 (56.5\%) were problematic internet users. The commonest online activity includes social networking (86.6\%), entertainment (77.3\%) and educational purposes (77.0\%). From multivariate analysis, problematic and addictive internet use was significantly more common among male students $(\mathrm{AOR}=2.47,95 \% \mathrm{Cl}[1.43,4.26])$, those who received study loan $(\mathrm{AOR}=1.93,95 \% \mathrm{Cl}[1.10$, 3.39]) and other types of funding $(\mathrm{AOR}=3.95,95 \% \mathrm{Cl}[1.59,9.80])$ compared to those on scholarships, and those who spent between four to ten hours a day accessing the Internet $(\mathrm{AOR}=2.43,95 \% \mathrm{Cl}[1.13,5.23])$ compared to those using the Internet for two hours or less a day. Conclusion: The prevalence of problematic and addictive internet use among respondents were higher compared to previous researches among Malaysian adolescents. It is recommended that an awareness programme on responsible use of the internet be conducted to prevent students from becoming addicted which may impact negatively on their educational performance and social life.

KEYWORDS: Internet addiction, Internet Addiction test, prevalence, undergraduate students, Malaysia

\section{INTRODUCTION}

In the present globalized era, the internet plays a pivotal part in the daily lives of approximately $40 \%$ of the world's population, with more than 3 billion internet users reported in 2016. Of these, $48.4 \%$ were from the Asian region. ${ }^{1}$ In Malaysia, the percentage of internet users was reported at $66.6 \%$ in 2014 based on a survey conducted by the Malaysian Communications and Multimedia Commission (MCMC). The survey also showed an

Corresponding author

Dr. Rosliza Abdul Manaf

Department of Community Health,

Faculty of Medicine and Health Sciences,

Universiti Putra Malaysia,

43400 Serdang, Selangor

Tel: 03-89472404/ 017-5667345

Email: rosliza_abmanaf@upm.edu.my increasing trend of internet on-the-go, interrelated with the upsurge of smartphone technology which made up $73.0 \%$ of the internet user base. ${ }^{2}$

While being a very useful technology that had advanced tele-communication paradigm in an exponential manner, the increasing use of the internet has led to many negative implications and complications, causing the emergence of clinical cases presenting abuse symptoms. ${ }^{3,4}$ In the wake of internet addiction, the American Psychiatric Association has included Internet Use Disorder in the appendix of the fifth edition of the Diagnostic and Statistical Manual for Mental Disorders. ${ }^{5}$

Internet addiction is considered to be a kind of technological addiction and is a subset of behavioural addictions such as compulsive gambling. 
It consists of at least three subtypes, i.e., excessive gaming, sexual preoccupations, and email/text messaging. All these subtypes are characterised with excessive use, withdrawal symptoms, developing tolerance of long usage and reportedly having negative repercussions including the involvement in arguments, lying, poor achievement, social isolation and fatigue. ${ }^{4}$ Various scales have been used in the measurement of internet addiction; this paper follows the dimensions of internet addictive behaviour in the Internet Addiction test (IAT) developed by Young et. al. ${ }^{5}$ According to IAT, internet addiction is denoted by the presence of the following symptoms including withdrawal and social problem, time management and performance, and reality substitute. ${ }^{6}$

A meta-analysis conducted by Cheng and $\mathrm{Li}$ in 2014 estimated the global prevalence of internet addiction at $6.0 \%{ }^{7}$ For the Asian region, a multicountry study of internet addiction among adolescents in China, Hong Kong, Japan, South Korea, Malaysia and the Philippines revealed the prevalence of $1.2 \%$ to $4.9 \%$ among adolescents age 12 to 18 years, with $2.4 \%$ of Malaysian adolescents reported being addicted. Another $35.1 \%$ of Malaysian adolescents were found having problematic internet use. ${ }^{6}$ Studies among university and college students revealed the prevalence of $5.2 \%$ addictive internet use in Iran, ${ }^{8} 2.9 \%$ in Jordan, ${ }^{9}$ $6.4 \%$ in China, ${ }^{10}$ and $17 \%$ in Taiwan. ${ }^{11}$

Internet addiction and problematic use of internet impact negatively on the individual and community well-being, more so among adolescents and young people. For university students, this condition has the potential to affect their academic performance and social interaction. This paper aims to describe the prevalence of problematic and addictive internet use among undergraduate students in a public university in Malaysia. The association between internet use and socio-demographic as well as other personal factors were also being examined and identified.

\section{MATERIALS AND METHODS}

A cross-sectional study was conducted from April to August 2016 amongst undergraduate students staying in College 17, Universiti Putra Malaysia. This residential college has the maximum capacity of housing 2500 occupants in four blocks of apartment- style accommodation. Altogether, there are 320 apartments, with eight students living in each unit. The majority are health sciences undergraduate students from the Faculty of Medicine and Health Sciences and the Faculty of Veterinary Medicine.

The sample size was calculated using the singleproportion formula with the expected prevalence rate of problematic and addictive internet use at $37.5 \%$ giving a minimum sample size of 216 students at $5 \%$ level of significance and margin of error at $10 \% .^{12}$ Cluster sampling was performed, with the list of apartments being the sampling frame. This involves listing out the apartment numbers obtained from the college administration office which were chosen randomly. During the study, 42 apartments were randomly selected. The students who lived in the selected apartment were approached by the research enumerator. All fulltime undergraduate students staying in the selected apartment, regardless of nationality and course were invited to participate in the study. The students who consented were given a self-administered questionnaire that has been pretested among a group of undergraduate students in a different residential college.

The questionnaire recorded information on sociodemography (age, gender, year of study and course taken), use of information technology gadgets (duration of use, device used to access Internet, ownership of smartphone and data access mode) and internet use. Internet addiction was measured using the 20-items Internet Addiction Test (IAT) with 5-point Likert scale which has been proven to be valid and reliable with overall alpha coefficient of 0.889 (95\% Cl: $0.884-0.895) .^{5,13}$ The IAT consists of three subscales which are withdrawal and social problem, time management and performance, and reality substitute. According to the classification by IAT, respondents who score 20-39 points are categorised as average internet users. Those with 40 -69 points are classified as problematic internet users who had encountered general life problems due to excessive internet use, while those scoring 70 points and above are categorized as addictive internet users who had significant amount of life problems as a result of excessive internet use. ${ }^{5,6}$

Data analysis was performed using IBM SPSS Statistics version 22. Descriptive analysis using frequencies and percentages was undertaken. 
Bivariate and multivariate analysis with simple and multiple logistic regressions respectively were conducted to identify for significant associated factors of internet addiction. Permission to conduct the study was obtained from the administration of the residential college, whereas research ethical clearance was obtained from the University's Ethical Committee for research involving human subject with the reference number of FPSK(EXP16Medic)U043.

\section{RESULTS}

A total of 323 undergraduate students aged between 19 to 24 years were invited to participate in this study. One student refused to participate, giving the response rate of $99.7 \%$. The sociodemographic characteristics and information on technology-related variables are shown in Table 1. About two-thirds $(64.6 \%)$ were female, reflecting the gender distribution favouring females in Malaysian public universities. The majority were of Malay ethnicity $(62.7 \%)$ and represented various year of study. Medical students comprised $35.4 \%$ of the respondents while the rest were from other health sciences courses including Veterinary Medicine, Biomedical Science, Nutrition, Nursing and Occupational and Environmental Health. The most popular information technology gadget owned by the respondents was the smartphone (93\%), followed by laptop (73.9\%) and Ipad or tablet (23.1\%). The result shows that $144(44.7 \%)$ of the respondents spent between four to ten hours a day on Internet, while $12(3.7 \%)$ respondents reported using the internet for more than ten hours a day.

Table 1: Socio-demography and information on technology-related variables $(\mathrm{N}=322)$

\begin{tabular}{|c|c|c|}
\hline Variables & Frequency & Percentage (\%) \\
\hline \multicolumn{3}{|l|}{ Gender } \\
\hline Female & 208 & 64.6 \\
\hline Male & 114 & 35.4 \\
\hline \multicolumn{3}{|l|}{ Year of Study } \\
\hline 1 & 51 & 15.8 \\
\hline 2 & 102 & 31.7 \\
\hline 3 & 77 & 23.9 \\
\hline 4 & 77 & 23.9 \\
\hline 5 & 15 & 4.7 \\
\hline \multicolumn{3}{|l|}{ Course taken } \\
\hline Medicine & 114 & 35.4 \\
\hline Bio-medical Science & 43 & 13.4 \\
\hline $\begin{array}{l}\text { Environmental and Occupational } \\
\text { health }\end{array}$ & 34 & 10.6 \\
\hline Dietetics & 14 & 4.3 \\
\hline Nursing & 24 & 7.5 \\
\hline Nutrition & 19 & 5.9 \\
\hline Veterinary Medicine & 74 & 23.0 \\
\hline \multicolumn{3}{|l|}{ Type of funding } \\
\hline Scholarship & 158 & 49.1 \\
\hline Study Loan & 116 & 36.0 \\
\hline Others & 48 & 14.9 \\
\hline \multicolumn{3}{|l|}{ Have own laptop } \\
\hline Yes & 254 & 78.9 \\
\hline No & 68 & 21.1 \\
\hline \multicolumn{3}{|l|}{ Have smartphone } \\
\hline Yes & 302 & 93.8 \\
\hline No & 20 & 6.2 \\
\hline \multicolumn{3}{|l|}{ Have Ipad/Tablet * } \\
\hline Yes & 74 & 23.1 \\
\hline No & 247 & 76.9 \\
\hline \multicolumn{3}{|c|}{$\begin{array}{l}\text { Average duration of Internet use per day } \\
\text { (hours) }\end{array}$} \\
\hline 2 hours or less & 41 & 12.7 \\
\hline Between 2 to 4 hours & 125 & 38.8 \\
\hline Between 4 to 10 hours & 144 & 44.7 \\
\hline More than 10 hours & 12 & 3.7 \\
\hline
\end{tabular}

* One missing data 
Figure 1 shows the online activities frequented by the respondents. The commonest activity that were engaged on was social networking (86.6\%), followed by entertainment $(77.3 \%)$ and using the internet for educational purposes $(77.0 \%)$. While $19.3 \%$ reported using the internet for online gaming, none reported using the internet for gambling. Further questioning on social networking revealed that the two most common network being used by the respondents were Facebook (82.3\%) and Youtube (64.6\%).

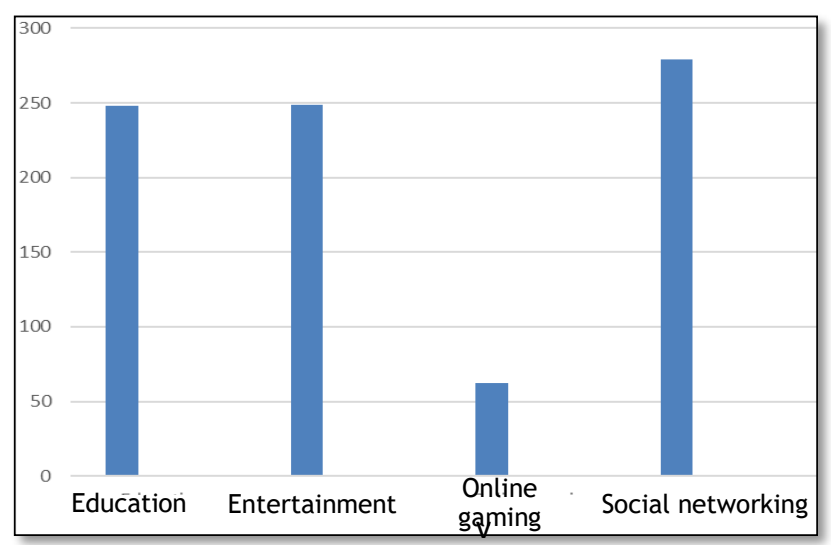

Figure 1: Number of respondents according to activities engaged during Internet use
The general description on internet use according to the score respondents obtained from the Internet Addiction Test (IAT) is described in Table 2. The detailed description of IATdefined categories according to respondents' sociodemographic characteristics and internet use is shown in Table 3. In general, $7.76 \%(95 \% \mathrm{Cl}[5.31 \%$, $11.21 \%]$ ) of the respondents were categorised as addictive internet users, while $56.5 \%(95 \% \mathrm{Cl}$ $[51.06 \%, 61.83 \%])$ fell under the category of problematic internet users.

Table 2: General description of internet use patterns according to IAT-defined categories $(\mathrm{N}=322)$

\begin{tabular}{lcc}
\hline Variables & Frequency & $\begin{array}{c}\text { Prevalence, \% } \\
(95 \% \mathrm{Cl})\end{array}$ \\
\hline Average & 115 & $35.71(30.68,41.09)$ \\
Problematic & 182 & $56.52(51.06,61.83)$ \\
Addictive & 25 & $7.76(5.31,11.21)$ \\
\hline
\end{tabular}

Table 3: IAT-defined categories of Internet Use according to socio-demographic characteristics and technologyrelated variables $(\mathrm{N}=322)$

\begin{tabular}{|c|c|c|c|}
\hline Variables & $\begin{array}{c}\text { Average Internet } \\
\text { users, } \\
\mathrm{n}(\%) \\
\end{array}$ & $\begin{array}{c}\text { Problematic Internet } \\
\text { users, } \\
\text { n (\%) }\end{array}$ & $\begin{array}{c}\text { Addictive Internet } \\
\text { Users, } \\
\text { n (\%) } \\
\end{array}$ \\
\hline \multicolumn{4}{|l|}{ Gender } \\
\hline Male & $28(24.3)$ & $70(38.5)$ & $16(64.0)$ \\
\hline Female & 87 (75.7) & $112(61.5)$ & $9(36.0)$ \\
\hline \multicolumn{4}{|l|}{ Year of Study } \\
\hline 1 & $12(10.4)$ & $32(17.6)$ & $7(28.0)$ \\
\hline 2 & $27(23.5)$ & $64(35.2)$ & $11(44.0)$ \\
\hline 3 & $32(27.8)$ & $40(22.0)$ & $5(20.0)$ \\
\hline 4 & 37 (32.2) & 38 (20.9) & $2(8.0)$ \\
\hline 5 & $7(6.1)$ & $8(4.4)$ & $0(0.0)$ \\
\hline \multicolumn{4}{|l|}{ Course taken } \\
\hline Medicine & $56(48.7)$ & $53(29.1)$ & $5(20.0)$ \\
\hline Non-medicine & $59(51.3)$ & 129 (70.9) & $20(80.0)$ \\
\hline \multicolumn{4}{|l|}{ Type of funding } \\
\hline Scholarship & $75(65.2)$ & $76(41.8)$ & $7(28.0)$ \\
\hline Study Loan & $33(28.7)$ & $70(38.5)$ & $13(52.0)$ \\
\hline Others & $7(6.1)$ & $36(19.8)$ & $5(20.0)$ \\
\hline \multicolumn{4}{|l|}{ Have own laptop } \\
\hline Yes & 944 (81.7) & 141 (77.5) & $19(76.0)$ \\
\hline No & $21(18.3)$ & $41(22.5)$ & $6(24.0)$ \\
\hline \multicolumn{4}{|l|}{ Have smartphone } \\
\hline Yes & $110(95.7)$ & $171(94.0)$ & $21(84.0)$ \\
\hline No & $5(4.3)$ & $11(6.0)$ & $4(16.0)$ \\
\hline \multicolumn{4}{|l|}{ Have Ipad/Tablet * } \\
\hline Yes & $35(30.4)$ & $34(18.8)$ & $5(20.0)$ \\
\hline No & $80(69.6)$ & $147(81.2)$ & $20(80.0)$ \\
\hline \multicolumn{4}{|c|}{$\begin{array}{l}\text { Average duration of Internet use per } \\
\text { day (hours) }\end{array}$} \\
\hline 2 hours or less & $22(19.1)$ & $18(9.9)$ & $1(4.0)$ \\
\hline Between 2 to 4 hours & $50(43.5)$ & $67(36.8)$ & $8(32.0)$ \\
\hline Between 4 to 10 hours & $42(36.5)$ & $89(48.9)$ & $13(52.0)$ \\
\hline More than 10 hours & $1(0.9)$ & $8(4.4)$ & $3(12.0)$ \\
\hline
\end{tabular}

* One missing data 
The results of the logistic regression analysing factors associated with problematic and addictive Internet use are shown in Table 4. HosemerLameshow chi-square test gave a $p$ value of 0.216 which indicating that the model fits the data adequately. Adjusted analysis showed that male students were 2.43 times more common to have problematic and addictive Internet use compared to female students $(95 \% \mathrm{Cl}[1.33,4.46])$. Problematic and addictive Internet use were about twice more common among students who received study loan and other types of funding such as their own savings or funded by family (adjusted $\mathrm{OR}=1.93 ; 95 \% \mathrm{Cl}[1.44$, 5.09]) when compared to those on scholarships. In terms of duration of Internet use, those who spent more than four hours a day accessing the Internet were more commonly to have problematic and addictive Internet use compared to students who used Internet for an average of two hours or less a day (adjusted OR=2.36; 95\% Cl [1.13, 5.44]). However, no significant difference were noted between those who used the Internet for an average of two to four hours a day.

Table 4: Factors associated with problematic and addictive internet use

\begin{tabular}{|c|c|c|c|}
\hline Variables & $\begin{array}{l}\text { Respondents with } \\
\text { problematic and } \\
\text { addictive Internet } \\
\text { use (N=207), } \\
\text { n (row \%) }\end{array}$ & $\begin{array}{l}\text { Unadjusted Odds } \\
\text { Ratio } \\
\qquad(95 \% \mathrm{Cl})\end{array}$ & $\begin{array}{l}\text { \# Adjusted Odds } \\
\text { Ratio } \\
(95 \% \mathrm{Cl})\end{array}$ \\
\hline \multicolumn{4}{|l|}{ Gender } \\
\hline Male & $86(75.4)$ & $2.21(1.33,3.67)$ & $2.43(1.33,4.46)$ \\
\hline Female & $121(58.2)$ & ref & ref \\
\hline \multicolumn{4}{|l|}{ Year of Study } \\
\hline 1 & $39(76.5)$ & $2.84(0.85,9.47)$ & \\
\hline 2 & $75(73.5)$ & $2.43(0.81,7.34)$ & \\
\hline 3 & $45(58.4)$ & $1.23(0.41,3.74)$ & \\
\hline 4 & $40(51.9)$ & $0.95(0.31,2.87)$ & \\
\hline 5 & $8(53.3)$ & ref & \\
\hline \multicolumn{4}{|l|}{ Course taken } \\
\hline Medicine & $58(50.9)$ & ref & ref \\
\hline Non-medicine & 149 (71.6) & $2.44(1.51,3.92)$ & $2.04(0.99,3.95)$ \\
\hline \multicolumn{4}{|l|}{ Type of funding } \\
\hline Scholarship & $83(52.5)$ & ref & ref \\
\hline Loan and other types & $124(75.6)$ & $2.80(1.74,4.50)$ & $1.93(1.44,5.09)$ \\
\hline \multicolumn{4}{|l|}{ Have own laptop } \\
\hline Yes & $160(63.0)$ & $0.67(0.43,1.35)$ & \\
\hline No & $47(69.1)$ & ref & \\
\hline \multicolumn{4}{|l|}{ Have smartphone } \\
\hline Yes & $192(63.6)$ & $0.58(0.21,1.64)$ & \\
\hline No & $15(75.0)$ & ref & \\
\hline \multicolumn{4}{|l|}{ Have iPad/tablet * } \\
\hline Yes & $39(52.7)$ & $0.53(0.31,0.98)$ & $0.71(0.35,1.45)$ \\
\hline No & $167(67.6)$ & ref & ref \\
\hline \multicolumn{4}{|c|}{$\begin{array}{l}\text { Average duration of Internet } \\
\text { use per day (hours) }\end{array}$} \\
\hline 2 hours or less & $19(46.3)$ & ref & ref \\
\hline Between 2 to 4 hours & $75(60.0)$ & $1.74(0.85,3.53)$ & $1.46(0.63,3.39)$ \\
\hline More than 4 hours & $113(72.4)$ & $3.04(1.50,6.17)$ & $2.36(1.13,5.44)$ \\
\hline
\end{tabular}

* One missing data

\# Adjusted for gender, course taken, type of funding, having iPad/tablet and average duration of Internet use per day. Nagelkerke $R^{2}=0.194$ 


\section{DISCUSSION}

The prevalence of addictive internet use in this study is $7.8 \%$, while the prevalence of problematic internet use stood at $56.5 \%$. In a simplified statement, these statistics show that one in every thirteen students have the chance to be an addictive internet user, and one in every two students have problematic internet use who had encountered general life problems due to excessive internet use. These findings corroborates with a Turkish study that used IAT as the diagnostic tool which reported almost similar prevalence of internet addiction at $9.7 \%$ among 1034 young adults surveyed. ${ }^{4}$ The prevalence in this study exceeded those reported by Mak et al. in 2014 who conducted a multi-countries epidemiological study on internet behaviours among adolescents aged 12 to 18 years. $^{7}$ In Mak et al.'s study, the Phillipines reported the highest prevalence of addictive internet use and problematic internet use which was $4.9 \%$ and $46.0 \%$ respectively, while Malaysian adolescents reported $2.4 \%$ prevalence of addictive internet use, and $35.1 \%$ of problematic internet use. This difference may be attributed by the different age groups being sampled. Compared to young adults, adolescents mainly live with their parents, hence receiving more parental supervision which has been proven to show an inverse relationship with internet addiction. ${ }^{14,15}$

This study revealed that problematic and addictive internet use were about two and a half times more common among male students compared to female. Similar findings of males being more predominant to having internet addiction compared to females were reported by studies conducted among students in Iran, ${ }^{16} \mathrm{China}^{17}$ and Japan. ${ }^{18}$ Studies have shown that the link between male gender and internet addiction may be mediated by the online activities that they were engaged upon. ${ }^{4}$ Activities such as online gaming which are highly addictive were mainly reported among males, whereas females were more involved in social networking. ${ }^{19}$ In addition, individual differences in personality traits such as impulsivity and poor self-control which are more common among males was also suggested as a plausible reason for the gender difference in the prevalence of internet addiction. ${ }^{4}$

Financial status was another significant factor associated with problematic and addictive Internet use in this study. Those with study loans and other sources of funding such as funded by family were reported to have higher prevalence of problematic and addictive Internet use compared to those on scholarships. The better financial support received by those on study loans and family fund may provide these students with more opportunities to have a better internet access, thus exposing them towards excessive use, as reported by previous studies. ${ }^{4,16}$

Majority of the respondents in this study reported spending an average of four to ten hours per day on the Internet. This is higher compared to the suggested normal duration of three hours or less per day that is considered as acceptable for healthy students. ${ }^{20}$ This average number has even been mutually agreed by another study done in Lebanon. ${ }^{21}$ On similar account, a Norwegian study reported that 4.3 hours on the Internet per week is spent by healthy normal students. ${ }^{22}$ Internet addiction has been reported to have a linear association with the duration of Internet use. ${ }^{4}$

The findings of the current study corroborate with this fact. While no significant difference in the prevalence of problematic and addictive Internet use was observed comparing those who spent less than two hours a day on internet with those spending between two to four hours, a higher prevalence was seen among those spending their time on internet between four to ten hours a day. With the current establishment of blended-learning and the use of on-line Learning Management System such as Moodle and Putrablast ${ }^{23}$, students are more exposed to longer hours of internet use which may put them at risk of becoming addictive to the internet.

In identifying the association between technology gadgets and Internet addiction, this study explored the ownership of three types of gadget which are the smartphone, laptop and tablet or Ipad. Similar to other findings on gadget ownership, a high proportion of the students owned a smartphone. ${ }^{2,7}$ In his study, Mak et. al .(2014) stated that Asian countries have a higher percentage of Internet addiction compared to the United States due to the increasing development of technology. ${ }^{7}$ While there is a common belief that mobile gadgets such as smartphones and tablets may have propagated Internet use among youth, this is not shown in the present study. 
While this study has provided an insight to the Internet behaviour of a group of youth in Malaysia, it has several limitations. Being a cross sectional study limits its ability to conclude any temporal causality. Second limitation is the presence of information bias as the questionnaires were selfadministered. To overcome this, proper explanation on the items was provided and confidentiality was assured through anonymity. Another limitation is the use of only one diagnostic questionnaire, i.e., the Young Internet Addiction test, or $\mathrm{IAT}^{12}$ to identify Internet addiction, allowing comparison of prevalence being made only with studies that have used the same diagnostic questionnaire. There are more than 20 types of diagnostic questionnaire being used to identify Internet addiction, however, the quality varied. ${ }^{4}$ The most commonly used is the IAT, hence the decision to adopt this diagnostic questionnaire to facilitate comparison.

\section{CONCLUSION}

The prevalence of problematic and addictive Internet use among undergraduate students in this study are higher compared to previous research among Malaysian adolescents. Male students, those with study loans and other sources of funding and spending longer duration on Internet were significantly associated with problematic and addictive Internet use among this population. It is recommended that an awareness programme on responsible use of Internet be conducted to the undergraduate students to prevent them from becoming addicted to Internet which may leave a negative impact to their education performance and social life.

Authors contribution (if more than one author) Author 1: Initiation of research idea, data analysis, writing the manuscript

Author 2: Writing the research proposal, data collection, data analysis, draft report

Author 3: Writing the research proposal, data collection, data analysis, draft report

Author 4: Reviewing the manuscript

\section{References}

1. Internet Users. Internet Live Stats 2017. Accessed on $8^{\text {th }}$ February 2017. Available at: http://www. Internetlivestats.com/Internetusers /
2. Malaysian Communication and Multimedia Commission (MCMC). Internet Users Survey 2014. !SSN 1823-2523

3. Young KS. Internet addiction: The emergence of a new clinical disorder. Cyberpsychology \& Behavior 1998;1:237-244

4. Kuss JD, Griffiths DM, Karila L et al. Internet addiction: a systematic review of epidemiological research for the last decade. Current Pharmaceutical Design 2014; 20:4026-4052.

5. Young KS. Internet addiction over the decade: A personal look back. World Psychiatry 2010; 9:91-91. doi:10.1002/j.2051-5545.2010.tb00279

6. Cheng C, Li AYL. Internet addiction prevalence and quality of (real) life: A meta-analysis of 31 nations across seven world regions. Cyberpsychology, Behavior, and Social Networking 2014; 17:755-760.

7. Mak K, Lai C, Watanabe H, et al. Epidemiology of Internet Behaviors and Addiction Among Adolescents in Six Asian

Countries. Cyberpsychology, Behavior, and Social Networking 2014; 17:720-728. doi:10.1089/cyber.2014.0139

8. Salehi M, Norozi Khalili M, Hojjat SK, et al. Prevalence of Internet Addiction and Associated Factors Among Medical Students From Mashhad, Iran in 2013. Iranian Red Crescent Medical Journal 2014; 16. doi:10.5812/ircmj.17256

9. Al-Gamal E, Alzayyat A, \& Ahmad MM. Prevalence of Internet addiction and its association with psychological distress and coping strategies among university students in Jordan. Perspectives in Psychiatric Care 2016;52:49-61.

10. Ni X, Yan H, Chen S, et al. Factors influencing Internet addiction in a sample of freshmen university students in China. Cyberpsychology \& Behavior 2009; 12:327-330.

11. Chou WP, Ko CH, Kaufman EA, et al. Association of stress coping strategies with Internet addiction in college students:

The moderating effect of depression. Comprehensive Psychiatry 2015; 62:27-33.

12. Lwanga SK, Lemeshow S. Sample size determination in health studies: a practical manual. World Health Organization. Geneva: 1991

13. Frangos CC, Frangos CC, Sotiropoulos I. A metaanalysis of reliability of Young's Internet 
Addiction Test. Proceedings of the World Congress on Engineering 2012 Vol 1, July 4-6, 202, London, U.K.

14. Yen CF, Ko CH, Yen JY, et al. (2009). Multidimensional discriminative factors for Internet addiction among adolescents regarding gender and age. Psychiatry and Clinical Neurosciences 2009; 63(3):357-364.

15. Chang FC, Chiu CH, Miao NF, et al. The relationship between parental mediation and Internet addiction among adolescents, and the association with cyberbullying and depression. Comprehensive Psychiatry 2015; 57:21-28.

16. Mazhari S. The Prevalence of Problematic Internet Use and the Related Factors in Medical Students, Kerman, Iran. Addict Health, Summer \& Autumn 2012; 4:3-4

17. Wang $L$, Luo J, Bai $Y$, et al. Internet addiction of adolescents in China: Prevalence, predictors, and association with well-being. Addiction Research \& Theory 2013; 21:62-69.

18. Sato T. Internet Addiction among Students: Prevalence and Psychological Problems in Japan. Japan Medical Association Journal 2006; 49:7-8

19. Heo J, Oh J, Subramanian SV et al. Addictive internet use among Korean adolescents: a national survey. PloS One 2014; 9(2):e87819.

20. Lin SS, Tsai CC. Sensation seeking and internet dependence of Taiwanese high school adolescents. Computers in Human Behavior 2002; 18:411-426

21. Hawi NS. Internet addiction among adolescents in Lebanon. Computers in Human Behavior 2012; 28:1044-1053. doi:10.1016/ j.chb.2012.01.007

22. Johansson A, Götestam KG. Internet addiction: characteristics of a questionnaire and prevalence in Norwegian youth (12-18 years). Scandinavian Journal of Psychology 2004; 45:223-229

23. Shamsudin MN. "Generasi $Y$ tidak sesuai ikut acuan lama." Berita Harian 2016 Aug 7: 11-11. 